\title{
Aproximações iniciais entre a praxiologia motriz e os jogos condicionados no ensino dos jogos esportivos coletivos
}

Initial approximations between motor praxiology and the games conditional in the teaching of the collective sports games

Aproximaciones iniciales entre praxiología motriz y juegos condicionales en la enseñanza de juegos deportivos colectivos

\section{William Daniel Bitencourt}

Universidade Federal de Santa Maria (CEFD/UFSM), Brasil

williambitencourt1989@hotmail.com

(iD) https://orcid.org/0000-0001-6994-5449

João Francisco Magno Ribas

Universidade Federal de Santa Maria (CEFD/UFSM), Brasil

ribasjfm@hotmail.com

(iD https://orcid.org/0000-0001-6296-628X

\author{
Antonio Guilherme Schmitz Filho \\ Universidade Federal de Santa Maria (CEFD/UFSM), Brasil \\ schmitzg@gmail.com \\ D https://orcid.org/0000-0002-7273-7066
}

\author{
Rosalvo Luis Sawitzki \\ Universidade Federal de Santa Maria (CEFD/UFSM), Brasil \\ rosalvols@hotmail.com \\ iD https://orcid.org/0000-0001-5768-6021
}

\begin{abstract}
Resumo:
Os Jogos Esportivos Coletivos são modalidades que apresentam, em sua lógica interna, peculiaridades que lhes dão um caráter de dinâmica para essas práticas motrizes. Nesse sentido, a aproximação de teorias que sistematizem o processo de ensino-aprendizagem é de suma importância para essas modalidades. Assim, esse estudo tem como objetivo estabelecer relações iniciais entre os principais conceitos da Praxiologia Motriz e dos Jogos Condicionados para o processo de ensino-aprendizagem. Para isso, realizou-se uma pesquisa teórica, apresentando definiçôes conceituais da Praxiologia Motriz e dos Jogos Condicionados, bem como as possíveis aproximações das mesmas dessas propostas. Dessa forma, a partir das discussões teóricas apresentadas, ficou evidente que o processo de ensino-aprendizagem pode ser pautado nessas arestas do conhecimento, pois apresentam expressivos caminhos para o processo de ensino-aprendizagem, possibilidades palpáveis para a prática pedagógica do professor (a), trazendo à tona conhecimentos relevantes para o ensino dos Jogos Esportivos Coletivos.
\end{abstract}

PalaVras-chaVe: Ensino esportivo, Praxiologia Motriz, Jogos Condicionados. 


\begin{abstract}
:
Collective sports games are modalities that have, in their internal logic, peculiarities which give them a dynamic character for these motor practices. In this sense, the approximation of theories that systematize the teaching-learning process is of utmost importance for these modalities. Thus, this study aimed to establish relationships between the main concepts of Motor Praxiology and the driving force of conditional games tied to their teaching-learning process. For this, we carried out a theoretical research, presenting conceptual definitions of Motor Praxiology and Conditional Games, as well as the possible approximations of these proposals in collective sports games. In this way, it was found that, from the results presented, the teaching-learning process can be guided in these areas of knowledge, since they present expressive and vast advances for the teacher's pedagogical practice, bringing forth new knowledge to the teaching of collective sports games.
\end{abstract}

KeYwords: Sports Education, Motor Praxiology, Games Conditional.

\title{
Resumen:
}

Los Juegos Deportivos Colectivos son modalidades que presentan, en su lógica interna, peculiaridades que les dan un carácter dinámico a estas prácticas de conducción. En este sentido, la aproximación de teorías que sistematizan el proceso de enseñanzaaprendizaje es de suma importancia para estas modalidades. Así, este estudio tiene como objetivo establecer relaciones iniciales entre los principales conceptos de Praxiología Motriz y Juegos Condicionales para el proceso de enseñanza-aprendizaje. Para ello, se realizó una investigación teórica, presentando definiciones conceptuales de Praxiología Motriz y Juegos Condicionales, así como sus posibles aproximaciones a estas propuestas. Así, a partir de las discusiones teóricas presentadas, se evidenció que el proceso de enseñanza-aprendizaje puede basarse en estas aristas del conocimiento, ya que presentan caminos expresivos para el proceso de enseñanza-aprendizaje, posibilidades tangibles para la práctica pedagógica del docente, sacando a la luz conocimientos relevantes para la enseñanza de los Juegos Deportivos Colectivos.

Palabras claVe: Educación deportiva, Praxiología Motriz, Juegos Condicionales.

\section{INTRODUÇÃo}

O esporte é um fenômeno cultural contemporâneo, uma invenção humana abrangente, ou seja, está ligado a toda a sociedade visto que mobiliza diversos seguimentos no dia a dia. O mesmo se constitui de diferentes modalidades esportivas, as quais assumem status de fenômenos globalizados, motivadores de grandes eventos internacionais e responsáveis por uma parcela significativa das manifestações políticas e de poder (Silva, Gallatti \& Paes, 2010).

As diferentes modalidades esportivas coletivas vêm ganhando espaço cada vez mais dentro do contexto social em que principalmente crianças e adolescentes se inserem para sua prática e com isso a necessidade de operacionalizar o processo de ensino-aprendizagem é um ponto de suma importância nesse contexto. Os Jogos Esportivos Coletivos (JECs) englobam modalidades como o Basquetebol, Handebol, Futebol, Futsal e Voleibol e essas práticas por si só constituem um excelente meio formativo (Mesquita, 1992), na medida em que sua prática é orientada de correta forma, induzindo o desenvolvimento de competências em vários planos, entre os quais se destaca os aspectos técnico-táticos, em que os aspectos técnicos irão balizar as principais ações motoras do jogo, e os aspectos táticos se darão de forma direta com as leituras de jogo e as tomadas de decisões a se executar a partir das ações de seus companheiros e adversários. Balizar esse processo de ensino-aprendizagem é essencial e a Praxiologia Motriz e os Jogos Condicionados a partir dos seus principais conceitos podem subsidiar esse processo.

A partir da complexidade na compreensão da lógica interna dos JECs, se percebe a necessidade de introduzir os conhecimentos desenvolvidos pela Praxiologia Motriz, a fim de melhor entender a modalidade, a partir de sua lógica de funcionamento e as possíveis formas de operacionalizar o processo de ensinoaprendizagem dos JECs. A Praxiologia Motriz é conceituada como a "Ciência da Ação Motriz" e especialmente das condições, modos de funcionamento e resultados de seu desenvolvimento (Parlebas, 2001, p. 354), as ações motrizes ${ }^{1}$ estão inscritas nas normas do jogo e, baseado nisso, o autor diferencia a ação motriz de qualquer outro movimento. Ao se remeter a Praxiologia Motriz o estudo da lógica interna dos jogos e esportes se caracteriza a partir de suas regras ou normas de funcionamento. A busca principal é desvelar o mundo dos jogos e esportes. 
Admitamos que cada parte de um dos JECs seja única; todos os encontros ludo-esportivos diferem um dos outros; todos tem sua própria história e estão salpicados de acontecimentos originais. Não obstante estas diferentes peripécias são resultantes de uma mesma matriz. Um jogo esportivo não é somente um puro fantasma entregado às extravagâncias subjetivas; é antes de tudo um corpo de regras. E esse corpo de regras irá impor sua regra ao corpo. Define as características objetivas do jogo, ou seja, sua lógica interna que irá gerar comportamentos, sem dúvida alguma diversos, mas todos marcados pelo mesmo carimbo (Parlebas, 1996, p.16).

A partir dos conhecimentos da Praxiologia Motriz, tal matriz teórica propõe uma classificação para os jogos e esportes, onde as práticas motrizes estão classificadas a partir dos pilares da lógica interna. Os Universais e o Sistema de Classificação CAI (Companheiro, Adversário, Incerteza), que são pautados na concepção que os indivíduos, participantes do sistema praxiológico, estabelecem interações com o entorno físico e com os outros possíveis participantes (Parlebas, 2001; Lagardera \& Lavega, 2003). Os praticantes do sistema motriz podem ter ou não a presença de companheiros e/ou adversários, e o espaço de ação pode ser incerto ou padrão (Parlebas, 2001; Lagardera \& Lavega, 2003). Sabe-se que, o entorno físico é caracterizado pela instabilidade ou a padronização do local, no qual, a prática motriz irá ser realizada.

Ao falar sobre os JECs se torna indispensável partir de um entendimento de como se definem os mesmos. Conforme Teodorescu (1984), essas modalidades podem ser definidas como uma atividade social organizada, na qual os jogadores estão agrupados em duas equipes em uma situação de rivalidade desportiva, visando à obtenção da vitória e fazendo uso de regras pré-estabelecidas. Acrescenta-se ainda a perspectiva de Garganta (1995), para quem os JECs apresentam dois traços fundamentais: a inteligência e a cooperação, sendo que a estes o autor soma a importância da comunicação.

Nesse sentido, os JECs vêm a ser tema de diversos estudos (Garganta, 1995; Graça, 1995; Graça \& Mesquita, 2002; Tavares, 2013; Bunker \& Thorpe, 1982; Mahlo, 1969; Kröger \& Roth, 1999; Gréhaigne, 2001, Bayer, 1994; Teodorescu, 1977), no que se refere a conceitos relacionados com seu processo de ensinoaprendizagem, esse necessita passar por uma reelaboração, na qual possa adotar diferentes significados, ou seja, que busque atender as necessidades atuais do ensino esportivo, de forma a superar e transpassar o ensino fragmentado em que o aluno é o sujeito principal desse processo. Segundo Daolio (2002), o esporte, precisa ser encarado, como um elemento que deve transcender a dimensão técnica operacional, no qual ensino de forma fragmentada, mecanizada e dissociada da lógica do jogo é ponto central do processo de ensinoaprendizagem.

Dessa forma a ação pedagógica do professor (a) é fundamental para que ocorra o processo de ensinoaprendizagem de uma maneira adequada, segundo Graça (1998), para que o aluno possa participar efetivamente das experiências de aprendizagem, é necessário que o professor (a) tenha conhecimento dos conteúdos dos jogos, da pedagogia do esporte e dos processos de ensino-aprendizagem. A fim de contemplar todos esses conceitos, aliados ao objetivo de um melhor processo de ensino-aprendizagem, emergem diferentes formas, métodos e metodologias de ensino no contexto dos jogos esportivos coletivos.

O método escolhido deverá facilitar o ensino-aprendizagem, bem como preparar o iniciante para o processo de treinamento, sem, contudo, tornar-se maçante ou desmotivá-lo. Deve ainda proporcionar situaçóes-problemas ou oferecer tarefas a executar que estejam adequadas à capacidade do aluno, proporcionando-lhe assim, momentos de prazer e alegria (Greco, 1998 , p. 40).

Ao adaptar uma modalidade esportiva ajustando suas características, se pode propor a sistematização de conhecimentos dos processos técnicos e táticos. Devido a este motivo se justifica a utilização de espaços reduzidos para a realização de adaptações técnico-táticas destas modalidades com o intuito de condicionar alguns jogos para se alcançar algum objetivo, assim surge à possibilidade de utilização dos Jogos Condicionados (Launder, 2001).

Tais práticas possibilitam a autonomia do sujeito, Bayer (1994), Garganta (1995) e Werner, Thorpe \& Bunker (1996), avaliam que o ensino dos JECs deve ser situado na compreensão das situações deparadas 
durante o decorrer do jogo, para isso direcionaram a escolha da utilização de jogos, brincadeiras e situações reduzidas de jogo (Jogos Condicionados).

Neste sentido, a sistematização dos Jogos Condicionados no processo de ensino-aprendizagem dos JECs, ao simplificar suas regras a fim de adequá-los aos praticantes e beneficiar a aprendizagem, é uma necessidade propositiva através das alterações que tornem o jogo a uma complexidade adequada as diversas situações as quais serão submetidos, assim propiciando aos alunos que já dominam um determinado jogo desafios constantes, de maior complexidade, e aos iniciantes um meio motivador através do jogo, assim instigando a resolução dos diferentes problemas que as alterações nas regras do jogo proporcionam.

As alterações na estrutura do jogo são de responsabilidade do professor (a), para facilitar alguns princípios da pedagogia do esporte e algumas das características do jogo sejam preservados, como a participação efetiva, a autonomia, a acessibilidade, a segurança e a motivação dos praticantes.

Um dos momentos da prática esportiva orientada que a PE se detém é que o primeiro contato sistematizado com uma modalidade esportiva mediada por um professor responsável, a fim de que o aprendiz tenha domínio básico e autonomia para prática esportiva (Blázquez, 1995).

Ao perceber isso, a busca de relacionar a Praxiologia Motriz com os Jogos Condicionados no processo de ensino-aprendizagem, pode vir a ser um caminho a auxiliar a prática pedagógica do professor (a), principalmente no que tange o entendimento do contexto do jogo e a materialização desse processo através dos Jogos Condicionados. Esses conceitos perpassam toda a estruturação e organização interna de funcionamento dos JECs, incluindo a sua classificação e os elementos que interferem diretamente nos diferentes momentos do jogo, bem como sua materialização no processo de ensino- aprendizagem. Nessa sistematização os conceitos de lógica interna, referenciados pela Praxiologia Motriz, são organizados e estabelecidos metodologicamente perpassando os caminhos apontados pelos Jogos Condicionados.

A partir dessa relação à ideia é oferecer ao professor novos conceitos para o planejamento de sua prática pedagógica, e assim atingir um êxito no processo de ensino-aprendizagem. No entanto, esse estudo limitouse mais em apresentar as implicações da Praxiologia Motriz, e descrever os conceitos que caracterizam sua lógica interna. Os Jogos Condicionados são apresentados como uma proposta metodológica que possibilita a materialização desses conceitos no processo de ensino-aprendizagem. Porém, não foi organizada nenhuma relação específica dos conhecimentos da Praxiologia Motriz com os Jogos condicionados de maneira aprofundada. Por isso, se torna importante sistematizar os principais elementos dos JECs a partir da Praxiologia Motriz e dos Jogos Condicionados, para tanto, tem-se como objetivo desse estudo estabelecer relações iniciais entre os principais conceitos da Praxiologia Motriz e dos Jogos Condicionados para o processo de ensino-aprendizagem.

\section{Metodologia}

Para tanto essa investigação se constitui como uma pesquisa de caráter teórico, que se dedica a desenvolver e discutir conceitos, estruturar quadros de referência e estudar teorias (Demo, 1995). Esse estudo também se configura de natureza exploratória, Richardson (2012) se refere que as pesquisas exploratórias buscam desvendar relações entre os fenômenos, no sentido de reconhecer e, sobretudo, delimitar essas possíveis aproximações conceituais entre diferentes campos. Nesse caso, aqui serão marcadas aproximações dos conhecimentos praxiológicos com os principais conceitos advindos dos Jogos Condicionados, no sentido de apurar o processo de ensino-aprendizagem voltado à compreensão do jogo.

Para seleção das obras contempladas, foram considerados os critérios apontados por Salvador (1986) para delimitação do referencial teórico, que são os parâmetros temático, linguístico, cronológico e as principais fontes. Consideraram-se, então, obras que tematizam os Jogos Condicionados e a Praxiologia Motriz, no que diz respeito a suas propostas teóricas, estruturações e aplicações em diferentes contextos. 
No que diz respeito à categoria de linguagem, a pesquisa apresentou maior quantidade de estudos em português devido à facilitação na interpretação teórica, bem como, obras em espanhol por serem bases teóricas da Praxiologia Motriz. Contudo, obras em outras línguas também foram utilizadas por serem de grande relevância para tornar a investigação mais criteriosa e apurada conceitualmente. Nesse sentido, optou-se por não realizar um recorte temporal para evitar a exclusão de referências primordiais em relação aos temas do estudo, o que justifica a utilização de todas as obras destacadas nessa investigação.

\section{Resultados e Discussões}

Os conhecimentos advindos da Praxiologia Motriz sistematizam os elementos referentes à lógica interna dos jogos e esportes. A partir desses princípios se destacam as interaçóes entre os jogadores, podem estabelecer relação com: material, tempo, local de prática e as interações que ocorrem entre os jogadores que compõem esse sistema praxiológico. Desse modo, a Praxiologia Motriz estrutura um Sistema de Classificação $(\mathrm{CAI})^{2}$, no qual esse busca orientar a organização de todas as práticas motrizes. Essa classificação é pautada a partir das interações que os jogadores estabelecem com o espaço e com os demais jogadores (as) (Figura1).

FIGURA 1

Sistema de Classificação CAI.

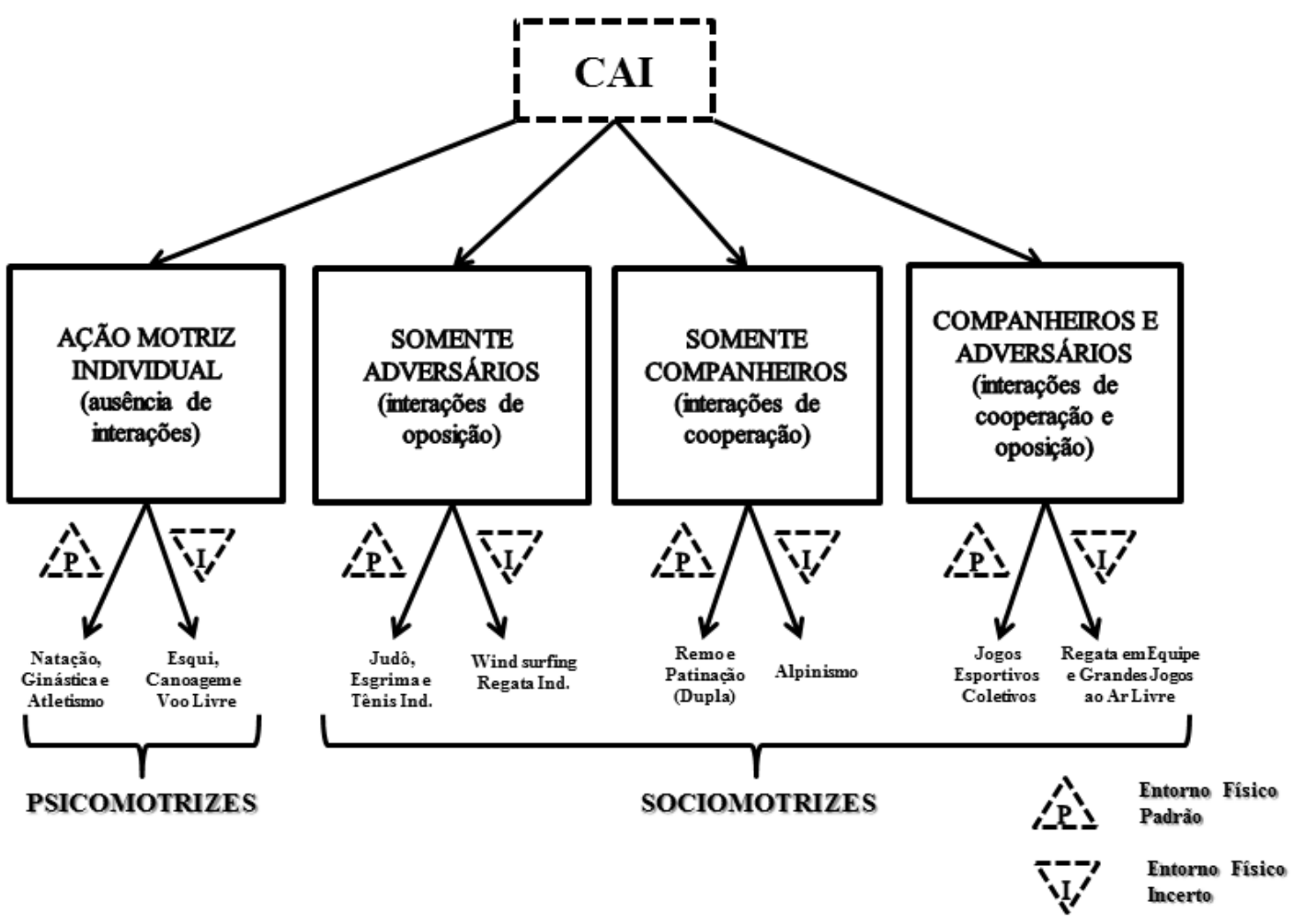

Fonte: Adaptada de Parlebas (1987, p. 18).

Da mesma forma que a Praxiologia Motriz estrutura uma classificação que agrupa as práticas motrizes a partir da lógica interna, esta teoria apresenta modelos que sistematizam as peculiaridades e os elementos internos de diversas modalidades, visto que, nem todas as características relevantes dos JECs ficam evidentes 
considerando apenas o sistema de classificação CAI. Logo, os Universais ${ }^{3}$ como modelos balizadores de organização de todas as práticas motrizes configuram um panorama específico, desmembrando a lógica do jogo, apenas para facilitar o entendimento, as características relevantes dos processos comunicativos e estratégicos que ocorrem no jogo.

No que se refere aos Jogos Condicionados, esses se sustentam a partir de situações do jogo formal com o objetivo de propor um aprendizado mais completo dos jogadores, organizando suas estruturas de atividades a partir da decomposição do jogo (jogos reduzidos, alteração do número de atletas, mudanças de regras e pontuações e condicionamento ao objetivo a se propor e alcançar), essa forma de jogos prima pela compreensão dos momentos do jogo e suas possíveis relações.

De forma concreta essas etapas se materializam no processo de ensino-aprendizagem, através do jogo sistematizado e da utilização de estruturas funcionais ${ }^{4}$, de caráter formal de forma sistemática e de complexidade crescente, levando sempre em conta os conhecimentos advindos dos alunos, respeitando os princípios que regulam o jogo, ainda se pode utilizar da variação do espaço, entre outras variações desde que essas não venham a interferir na lógica de funcionamento do jogo. Portanto, os Jogos Condicionados, através de sua base teórica que está centrada no desenvolvimento da inteligência tática, possibilita ao jogador o conhecimento de "o que fazer" e "como fazer" no jogo, onde a técnica surge em função das questões táticas de forma orientada e provocada. Esses conhecimentos mínimos de forma correta em sua aplicação podem vir a possibilitar aos jogadores o desenvolvimento do processo de leitura de jogo, correta aplicação dos princípios do jogo, e uma tomada de decisão eficaz e, a partir desse, a execução da ação motriz acertada para a resolução dos problemas encontrados no jogo.

Dessa forma, os conceitos aprofundados de forma inicial nessa revisão teórica adotaram um caráter essencial para a ideia que será realizada no desenvolvimento desse estudo. Ou seja, sustentar as aproximações iniciais conceituais da Praxiologia Motriz com os Jogos Condicionados. Assim será constituída a relação dessas duas teorias, considerando os modelos Universais da Praxiologia Motriz, com a organização das estruturas para o processo de ensino-aprendizagem através dos Jogos Condicionados em forma de situações de jogo.

\section{Rede de Comunicação Motriz e os Jogos Condicionados}

Nos JECs, elemento importante que acontece durante o jogo são as trocas de mensagens, essas se tornam essenciais para que se atinja a eficácia no jogo, esses processos acontecem porque essas modalidades possuem interações de cooperação e oposição. A relevância do processo de comunicação entre os jogadores se apresenta medida que desde o primeiro momento do processo de ensino-aprendizagem dos JECs, assim os jogadores vão compreendendo e acrescentando informações de formas de comunicar-se com os companheiros e contracomunicar-se com os adversários (Garganta, 1998). Para que esses conceitos sejam comprovados na prática, esses carecerão ser solicitados e estimulados em situações de jogo (Garganta, 1998). A partir desses pressupostos se pode perceber uma possibilidade real articulação existente entre a Rede de Comunicação Motriz e o Jogos Condicionados.

De maneira geral uma eficiente comunicação é aquela que mediante a um amplo repertório de difusão de informações minimiza o trabalho de interpretação que o jogador deve realizar para sua apropriação (Fotía, 2003).

Em um treinamento de Basquetebol, por exemplo, que envolva jogadas ensaiadas e que não conte com oposição de um adversário, um jogador pode ter um significativo êxito na execução das jogadas. Porém, em um contexto de jogo, esses resultados podem se tornar negativos, tendo em vista um despreparo em relação à leitura do adversário e/ou a forma com que as mensagens são passadas aos companheiros. 
Esses processos devem ser contemplados no processo de ensino-aprendizagem dessas diversas modalidades. Para isso se deve utilizar formas de ensino que considerem as interações, de modo a possibilitar a elucidação da rede de comunicação motriz. Premissa importante essa para o processo de ensino-aprendizagem dessas modalidades é que esses sistemas não podem ser compreendidos a partir de um ponto de vista analítico, e sim, considerar a partir dos componentes e princípios de sua lógica interna (Fotía, 2013). Portanto, a rede de comunicação motriz se relaciona com os Jogos Condicionados à medida que esse modelo materializa suas estruturas de atividades por meio de estruturas funcionais, e as relações de nível de jogo a serem estabelecidas de forma crescente na aplicação da complexidade das mesmas.

Neste sentido, a utilização das estruturas funcionais viabiliza operacionalizar e concretizar a aquisição e o desenvolvimento técnico-tático (Lima, 2008). Para corroborar (Greco, 2012), afirma que, por esse motivo se torna necessário expandir os conhecimentos táticos, de modo conceitual e prático. Logo, o processo de ensino-aprendizagem, através das estruturas funcionais, proporciona inúmeras situações problema de jogo, de forma a apresentar ao jogador uma tarefa que lhe requeira a adequada solução a cada situação nova de jogo. Essas particularidades viabilizam as interações existentes nos JECs, ou seja, os jogadores podem cooperar e opor ao mesmo tempo, fomentando a operacionalização do processo de comunicação motriz.

A comunicação e a contracomunicação que fazem parte da rede de comunicação motriz, e indicam a possibilidade de transmissão de mensagens que os jogadores podem executar com clareza aos seus companheiros e de forma codificada para seus adversários no contexto do jogo. A partir dessas trocas de mensagens existentes no decorrer no jogo, a estruturação dos Jogos Condicionados contemplam estruturas de atividades capazes de materializar esses processos essenciais para o ensino-aprendizagem desses elementos.

Cabe ressaltar que os processos estruturados pela rede de comunicação motriz estão diretamente ligados ao processo de leitura das situações do jogo. Pode-se assim perceber outra relação existente entre esse modelo, com os Universais e com o ensino através dos Jogos Condicionados. Os processos de comunicação motriz estão relativamente ligados a eficiente leitura de jogo e a eficaz tomada de decisão (Lavega, 2008). Isso acontece devido ao alto grau de combinações entre os jogadores que fazem parte do sistema praxiológico, regido por um sistema de codificação e decodificação de mensagens (Ribas, 2014).

O nível de compreensão das funções de jogo e as comunicações que irão ocorrer são medidos pela leitura de jogo, pois, através desse procedimento o jogador passa a ter um conhecimento sobre as potencialidades e fragilidades, tanto dos seus companheiros quanto dos seus adversários e, dessa forma, atingir a eficácia na ação motriz para resolver as situações problemas (Ribas, 2014).

\section{Rede de interação de marca e Sistema de pontuação e os Jogos Condicionados}

A rede de interação de marca busca dar conta de ressaltar o que deve ser feito para vencer o jogo, ao salientar que tipo de interação motriz é necessário estabelecer para obter a vitória em determinada prática motriz. Lagardera e Lavega (2003) apresentam as variáveis da rede de interação de marca, as quais podem ser antagônica (êxito a partir da oposição), cooperativa (triunfo pela cooperação) ou mista (sucesso pode provir da cooperação e/ou da oposição). A exemplo, temos no Handebol quando a equipe está no momento ataque e o jogador de posse de bola necessita realizar um passe para um de seus companheiros é de entendimento que se facilite a leitura de seus companheiros para realização do passe, e dificulte a leitura do adversário, para que o mesmo não execute uma intercepção do mesmo e recupere a posse de bola.

O sistema de pontuação é bastante simples e de comum entendimento pela maior parte do público que se interessa pelos JECs. Durante uma partida de Futebol, por exemplo, essa ocorre dentro de um limite de tempo e, ao seu término, a equipe que mais fez gols se torna a vitoriosa, ainda, pode haver empate, ou ovencedor entre duas equipes que empataram também pode ser decidido através de prorrogação e/ou disputa por pênaltis.

Os Jogos Condicionados, a partir de sua estruturação e possibilidades de atividades através do jogo (formal ou decomposto em estruturas funcionais), se relacionam com a rede de interação de marca no momento 
em que proporcionam, através das relações existentes no jogo, atividades em que o aluno (a) compreenda o objetivo a se alcançar para vencer o mesmo proporcionando diferentes pontuações, em que essas atendam os diferentes objetivos propostos durante o condicionamento advindo do jogo. A respeito do sistema de pontuação o mesmo em si é voltado para o condicionamento de diversas situações problema e a pontuação pode ser relacionada a alcançar com êxito do problema proposto, de forma como pontuação extra ao sistema de pontuação original pertencente à lógica interna do jogo. Exemplo para isso é uma atividade na modalidade Futsal para construção de gols de dentro da área de meta, se o êxito for alcançado à equipe recebera dois tentos ao em vez de um conforme é estabelecido pela regra do jogo.

\section{Sistema de Troca de Papéis e os Jogos Condicionados}

Outro modelo Universal a ser evidenciado é o dos papéis, contudo entender esses se torna relevante à medida que orienta os jogadores em relação aos seus direitos e as proibições apresentadas pelo jogo (Parlebas, 2001; Lagardera \& Lavega, 2003). Os mesmos determinam, sem qualquer contradição, a forma como os jogadores do sistema praxiológico poderão agir nesse contexto, pois são pautados pelo regulamento, é a partir dos papéis que os jogadores conhecem as possibilidades de ação referentes às situações apresentadas pelo jogo. Assim, na medida em que o jogador assume um papel em uma partida ou determinada situação da mesma, surgem às possibilidades de ações motrizes a serem concretizadas. Ao mesmo tempo, as relações de interação influenciarão na utilização das ações motrizes (Marques Filho, 2017). Dessa forma, os jogadores traçam as estratégias de ação e conduta para superar suas limitações, referentes às obrigações impostas pelas regras do jogo, e executar as ações motrizes necessárias para resolver as situações problema.

Ao exemplo do Futsal, temos seis funções goleiro, goleiro linha, fixo, ala esquerda, ala direita e pivô, as quais serão assumidas com o sistema de jogo adotado a partir de determinado momento do jogo. Já os papéis serão ações estratégicas que o jogador pode assumir são: jogador com a bola, jogador sem a bola da equipe que tem a posse de bola e jogador da equipe sem a bola. Vamos esclarecer melhor estas relações já que destacam outra característica dos jogos coletivos utilizando-se do Futsal.

- Jogador com a bola: Nesta situação no Futsal, temos as seguintes ações: colocar em jogo a bola, avançar com a bola, proteger a bola, passar a bola, chutar a gol, conduzir e retê-la para passar o tempo, driblar, colocar-se em posição de ataque, perder a bola, fazer falta ou violar a regra e receber falta.

- Jogador sem a bola da equipe com a bola: avançar em direção ao ataque, ocupar uma posição no sistema, desmarcar-se, bloquear, fintar, ampliar espaços, reduzir espaços, ajudar a um companheiro, pedir a bola, receber a bola, esperar, fazer falta ou violar a regra e receber falta.

- Jogador da equipe sem a bola: retornar à defesa, ocupar uma posição no sistema, reduzir espaços, ampliar espaços, antecipar-se, ajudar um companheiro, interceptar ou desviar a bola, recuperar a bola, fazer falta e receber falta.

Mesmo a partir dos demais Universais destacados anteriormente, o entendimento dos papéis dificilmente irá ocorrer se o processo de ensino-aprendizagem for centrado por uma concepção tecnicista ${ }^{5}$, voltada na repetição da técnica, pois sua dinâmica de troca de papéis está inteiramente ligada ao jogo. Nesse sentido, é indispensável que o modelo de ensino proporcione situações de atividades que contemplem as interações existentes nos JECs. Os Jogos Condicionados direcionam o processo de ensino-aprendizagem através de estruturas de atividades que beneficiam a manifestação dessas interações. Portanto a compreensão dos papéis se torna aberta, bem como sua dinâmica de troca, visto que esses procedimentos estão sendo materializados nas situações didáticas. 


\section{Sistema de Troca de Subpapéis e os Jogos Condicionados}

Como apresentado anteriormente, os papéis permitem aos jogadores a compreensão das possibilidades de ações motrizes que podem ser executadas. Esse aspecto remete diretamente aos subpapéis, definido como um comportamento que caracteriza a sequência motriz, ou seja, um conjunto de possibilidades de ações motrizes (Parlebas, 2001). Por estar diretamente ligado ao papel, o subpapel também possui um sistema de troca, pois as possibilidades de ações (subpapel) que o jogador pode executar são diferentes em relação a cada um dos papéis existentes. Nesse sentido, o processo de ensino-aprendizagem deve contemplar estruturas de atividades que permitam aos jogadores essa compreensão. Os Jogos Condicionados, por sua vez, proporcionam aos jogadores, na maior parte do tempo, que esses estejam atuando considerando os princípios da lógica interna da modalidade ao qual se esta ensinando, e, logo, estabelece a compreensão das potencialidades de permissões e obrigações, definindo assim os subpapéis.

O Handebol, por exemplo, uma modalidade de cooperação e oposição, em que essas interações ocorrem simultaneamente, a relação entre atacar-defender é indissociável, e ocorrem ao tempo todo visto os objetivos gerais de ataque, manter a posse de bola por um determinado tempo e finalizar na meta adversária, e os gerais de defesa, que se dá com o objetivo de recuperar a posse de bola, evitar as ações adversárias e evitar que a bola entre em sua baliza. Dessa forma, ao considerar o momento do jogo em que sua equipe se encontra e o papel assumido pelos jogadores, o participante irá assumir um subpapel, o qual irá permitir a realização de outros subpapéis. Esse entendimento possibilitara ao jogador uma melhor compreensão da lógica interna do jogo e com isso desenvolver sua tomada de decisão e melhor resolução das situações problemas.

Os Jogos Condicionados partem da premissa de desenvolver a inteligência tática nos jogadores, e, a partir de suas estruturas de atividades, proporciona esse desenvolvimento. Desta forma se verifica que a capacidade tática está atrelada ao desenvolvimento do processo de leitura de jogo, na qual se faz necessário relacionar os subpapéis aos Jogos Condicionados. Esse modelo de ensino contempla as estruturas necessárias para que os jogadores consigam conhecer, compreender e definir suas ações motrizes eficazes para atingir o objetivo no jogo e a Praxiologia Motriz apresenta instrumentos para balizar e potencializar esta compreensão.

Partindo assim das descrições apresentadas acima, é concreta a possibilidade da importância de se construir um processo de ensino-aprendizagem dos JECs que contemple os seus elementos primordiais. Entender a lógica interna dessas modalidades é de suma importância para a compreensão de todos os princípios que emergem do jogo, desde as leituras e interpretações dos companheiros e adversários, até a execução da ação motriz acertada. As ações motrizes utilizadas para resolver as situações problemas que o jogo impõe são mediadas pelos conhecimentos destacados na lógica interna (interações de cooperação e oposição, rede de comunicação, sistema de pontuação, interação de marca, gestemas, praxemas, papel e subpapel), por isso a eficácia na sua execução está atrelada ao entendimento dos conceitos em cada modalidade esportiva (Lanes, Marques Filho, Souza, Fagundes \& Oliveira, 2017). Para isso, se faz necessária à utilização de formas de ensino que possibilitem o desenvolvimento técnico-tático, bem como o aperfeiçoamento das capacidades de resolução das situações problema e tomada de decisão, considerando os elementos da lógica interna (Ribas, 2014).

\section{Códigos Gestêmico e Praxêmico e os Jogos Condicionados}

Dando sequência a partir das premissas acima descritas, se apresentam dois Universais que possuem objetivos semelhantes aos destacados pela rede de comunicação motriz. A troca de mensagens através dessa rede de comunicação é um elemento de grande relevância, contudo, é necessário um modelo que permita identificar as categorias de transmissão e interpretação dessas mensagens existentes no contexto do jogo. 
Nesse sentido, os gestemas e os praxemas se tornam procedimentos de grande valia para esse momento. Com isso, os gestemas e os praxemas, caracterizados respectivamente como gestos mais "grossos" e "ações (signos) mais sutis" possibilitando ao jogador compreender, transmitir e interpretar as ações motrizes, tanto dos ou para os companheiros, quanto dos ou para os adversários. Exemplo de gestemas, no Voleibol temos a ação de levantar o braço pedindo a bola para atacar ou indicando a direção para onde irá se deslocar e realizar o mesmo, ou até mesmo no Basquetebol em uma jogada ensaiada em que um determinado jogador anuncia qual jogada treinada será realizada levantando a mão marcando o número da jogada.

Para exemplificar os praxemas, podemos utilizar a leitura de um goleiro que tenta antecipar o chute de um jogador adversário, e ao fazer essa determinada leitura consegue efetuar a defesa. Ou até mesmo um jogador que consegue ler que quando o goleiro irá repor a bola com a mão direita, esse jogador consegue se antecipar pois sabe que a grande maioria dessa ação pode ser uma reposição de bola longa por parte do goleiro.

Assim, o processo de leitura e compreensão do jogo, desenvolvido através dos Jogos Condicionados no qual a inteligência tática é potencializada, aumenta a probabilidade de eficácia na execução da ação motriz necessária para resolver a situação problema.

Partindo dos gestemas e praxemas serem descritos como o comportamento dos jogadores, se torna necessário que, para atingir uma boa leitura dessas condutas individuais e coletivas se faz necessário ajustar situações reais, ou estruturas de atividades semelhantes ao jogo formal. Os Jogos Condicionados, como supracitado, tem como sua principal vantagem, o desenvolvimento do processo de ensino-aprendizagem por meio de situações de jogo, materializadas pelas estruturas funcionais, possibilitando assim, a inteligência tática dos participantes (Garganta, 1995).

Os gestemas e praxemas, somente são compreendidos por meio de estruturas de atividades que materializam as interações de cooperação e oposição, pois, só se pode ler o comportamento gestual ou corporal de outros jogadores se ambos estiverem interagindo. Nesse sentido, os Jogos Condicionados pode vir a atingir o objetivo condicionador de proporcionar formas de atividades capazes de abranger o ensino-aprendizagem das interações existentes nos JECs.

Assim, a possibilidade de articulação inicial entre a Praxiologia Motriz aos elementos presentes nos Jogos Condicionados visa superar algumas barreiras até então aplicadas por concepções ultrapassadas de ensino, que estão bastante difundidas nas ciências do esporte. A Praxiologia Motriz, permite reconhecer e desvelar as estruturas e conjuntos de características importantes para o alcance de uma compreensão de jogo. Essa teoria organiza os conhecimentos da lógica interna, bem como as estruturas e modelos de definição desses elementos, que são de grande importância para a execução das ações motrizes que emergem dos JECs. Os Jogos Condicionados, por sua vez, busca proporcionar estruturas de atividade didaticamente organizadas, através de situações de jogo, visando o desenvolvimento das capacidades e habilidades técnico-táticas dos jogadores.

Portanto, a Praxiologia Motriz contempla os elementos importantes para a compreensão dos JECs e os Jogos Condicionados apresenta de forma materializada situações fundamentais para que esses elementos balizadores da lógica interna dessas modalidades. Com isso, o processo de ensino-aprendizagem se estrutura a partir dos conhecimentos importantes referentes à lógica de funcionamento do jogo, bem como, uma forma de ensino que organiza esses conceitos, de modo a possibilitar que a prática pedagógica do professor (a) supere as ideias até então vistas em alguns processos de ensino-aprendizagem ultrapassados. A partir do exposto se apresenta a figura dois, que elucida de forma simplificada a relação entre os Jogos Condicionados e a Praxiologia Motriz. 
FIGURA 2

Processo de ensino-aprendizagem a partir da relação entre Praxiologia Motriz e os Jogos Condicionados.

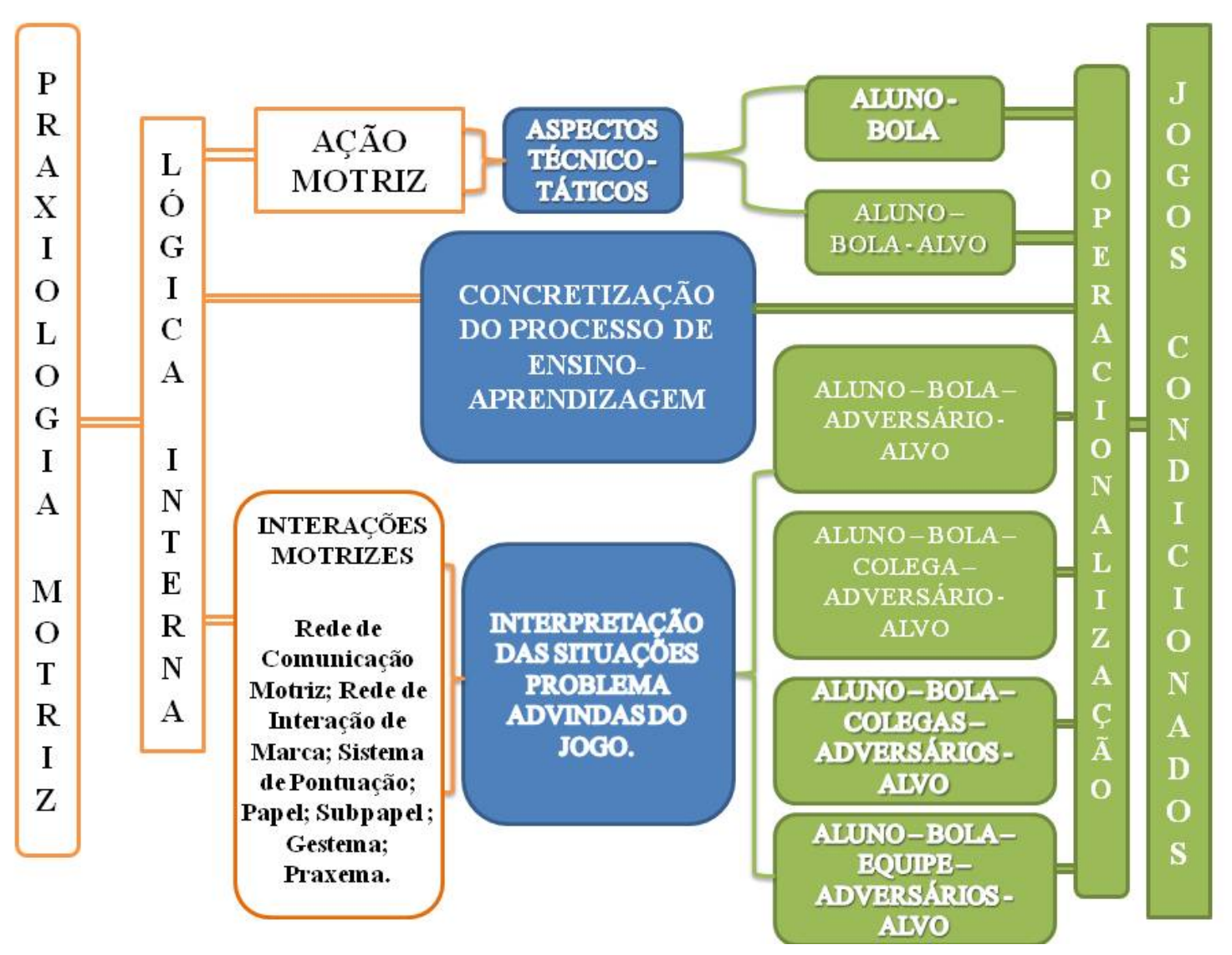

Fonte: Elaborada pelos autores.

\section{CONCLUSÃo}

Ao longo do texto, se apresentou a importância da Praxiologia Motriz como a teoria que explica e organiza a dinâmica e o funcionamento dos JECs. Da mesma forma, os Jogos Condicionados por sua vez, se constitui no conhecimento que operacionaliza esses conceitos de maneira inovadora, superando o ensino descontextualizado do jogo.

Esse estudo se debruçou em estabelecer relações iniciais entre duas proposições teóricas, visto que, esse suporte é importante para categorizar alguns conhecimentos que deverão ser considerados nas proposições didático-pedagógicas dos professores (as). E com isso, no desenvolver e descrições acerca desses conhecimentos ficou claro a relevância da Praxiologia Motriz como a teoria de análise de jogo, que se apresenta como suporte conceitual da compreensão e explicação da lógica de funcionamento dos JECS. Dessa forma, é possível compreender as interações motrizes de cooperação e oposição, que originam os modelos operativos que desvelam a lógica interna dessas modalidades. Dessa forma, os Universais se destacam como elementos fundamentais no entendimento da dinâmica de funcionamento dos JECs.

Os Jogos Condicionados se apresenta como uma importante ferramenta na operacionalização do processo de ensino-aprendizagem dessas modalidades. Assim, se pode perceber através das descrições que, por orientar o ensino a partir de princípios táticos, os Jogos Condicionados permite desenvolver e integralizar esses princípios de maneira condizente, através do jogo e com as demandas que emergem do mesmo. Nesse intuito, 
esse modelo de ensino operacionaliza o processo de ensino-aprendizagem dos JECs a partir de uma estrutura que possibilita desenvolver os aspectos técnicos e táticos inerentes a essas modalidades.

Dessa forma, foi possível articular os conhecimentos da Praxiologia Motriz com os Jogos Condicionados, de forma a relacionar os Universais com os Jogos Condicionados. Os Universais surgem como conhecimentos balizadores que estruturam a lógica interna dessas modalidades e permitem a compreensão da sua dinâmica de funcionamento. Os Jogos Condicionados assim possibilitam operacionalizar situaçóes de jogo que contemplam todos os elementos de interação do processo de ensino-aprendizagem. As situações de jogo possibilitam a materialização das interações motrizes dos diferentes JECs e, automaticamente, os modelos universais oriundos desses preceitos emergem no processo.

Vale salientar que a Praxiologia Motriz não é um método de ensino e tão pouco uma concepção pedagógica, mas sim uma teoria que proporciona conceitos que merecem e devem ser mais bem arraigados. Por isso, é importante a utilização de métodos não lineares que possibilitem a materialização desses conceitos sustentados pela por essa matriz teórica. Atualmente, a discussão acerca dos métodos vem se aumentando, no qual se tem apresentado diversos modelos baseados nessas características de ensino. Dessa forma, constatou-se de forma inicial, a partir dos resultados da pesquisa, que o processo de ensino-aprendizagem pode ser pautado nessas arestas do conhecimento, pois apresentam expressivos e vastos avanços para a prática pedagógica do professor (a), trazendo à tona novos conhecimentos para o ensino dos JECs.

À medida que se ofereceu algumas contextualizações acerca da Praxiologia Motriz, torna-se importante investir em estudos que avaliem os conceitos ponderados ao longo dessa pesquisa. É importante que os treinadores proponham intervenções balizadas pelos conhecimentos da Praxiologia Motriz, articulando essas propostas teóricas as suas metodologias para o processo de ensino-aprendizagem. Nesse momento as discussões abordadas até aqui fornecem um valioso subsídio teórico para balizar esse processo, bem como para o conhecimento do professor (a).

\section{REFERÊNCIAS}

Bayer, C. (1994). O ensino dos desportos colectivos. Dina livros. Lisboa.

Sánchez, D. B. (1995). La iniciación deportiva y el deporte escolar. Inde.

Bunker, D., \& Thorpe, R. (1982). A model for the teaching of games in secondary physical education. Bulletin of Physical Education, 18, 5-8.

Daolio, J. (2002). Jogos esportivos coletivos: dos princípios operacionais aos gestos técnicos-modelo pendular a partir das idéias de Claude Bayer. Revista Brasileira de Ciência e Movimento, 10(4), 99-104.

Demo, P. (1995). Metodologia cientifica em ciências sociais.

Fotia, J. A. (2003). La comunicación en el voleibol. Lecturas: Educación fisica y deportes, (62), 19.

Fotia, J. (2013). Voleibol, lógica interna e iniciación. AcciónMotriz, 10, 76-83.

Garganta, J. (1995). Para uma teoria dos jogos desportivos coletivos. In: GRAÇA, A.; OLIVEIRA, J. O ensino dos jogos desportivos.

Garganta, J. (1998). O ensino dos jogos desportivos colectivos. Perspectivas e tendências. Movimento (ESEFID/ UFRGS), 4(8), 19-27.

Graça, A. (1998). Os comos e os quandos no ensino dos jogos. O ensino dos jogos desportivos, 2, 27-34.

Graça, A., \& Mesquita, I. (2002). A investigação sobre o ensino dos jogos desportivos: ensinar e aprender as habilidades básicas do jogo. Revista Portuguesa de Ciências do Desporto, 2(5), 67-79.

Greco, P. J. (1998). Iniciação esportiva universal: metodologia da iniciação esportiva na escola e no clube. Belo Horizonte: UFMG, 2, 305.

Greco, P. J. (2012). Metodologia do ensino dos esportes coletivos: iniciação esportiva universal, aprendizado incidental-ensino intencional. RevMineira Educ Fis UFMG, 20(2), 151. 
Gréhaigne, J. F. (2001). La organización del juego en el fútbol. Inde.

Kröger, C., \& Roth, K. (1999). Ballschule: ein ABC für Spielanfänger. Hofmann.

Lagardera, F. O., \& Lavega i Burgués, P. (2003). Introducción a la praxiología motriz. Editorial Paidotribo.

Lanes, B. M.; Marques Filho, C. V.; Souza, D. L.; Fagundes, F. M.; Oliveira, R. V. de. (2017). Voleibol e a Praxiologia Motriz. In: RIBAS, J. F. M. (ORG.) Praxiologia Motriz na América Latina: aportes para a didática na Educação Física. Ijuí: Editora Unijuí, p. 313-320.

Launder, A. G. (2001). Play practice: The games approach to teaching and coaching sports. Human Kinetics.

Lavega, P. (2008). Classificação dos jogos, esportes e as práticas motrizes. Jogos e esportes: fundamentos e reflexóes da Praxiologia Motriz, 81-104.

Lima, C. O. V. (2008). Desenvolvimento do conhecimento tático declarativo e processual no processo de ensinoaprendizagem-treinamento do voleibol escolar.

Mahlo, F. (1969). O acto táctico no jogo. Lisboa: Compendium.

Marques Filho, C. V. (2017). A estruturação do futebol e seus elementos pedagógicos: uma visão a partir da Praxiologia Motriz. 2017. 78 f, (Dissertação (Mestrado em Educação Física) - Universidade Federal de Santa Maria).

Mesquita, I. (1992). Voleibol-Abordagem Específica. Educação Física na Escola Primária (Iniciação Desportiva), 77-89.

Parlebas, P. (1987). Perspectivas para una Educación Física Moderna. Unisport. Málaga.

Parlebas, P. (1996). Los universales de los juegos deportivos. Praxiología motriz, 1(0), 15-29.

Parlebas, P. (2001). Léxico de praxiología motriz. Paidotribo.

Richardson, R. J. (2012). Pesquisa social: métodos e técnicas. 14. Reimpr. São Paulo: Atlas.

Ribas, J. F. M. (Ed.). (2014). Praxiologia motriz e voleibol: elementos para o trabalho pedagógico. Editora Unijuí.

Salvador, Â. D. (1986). Métodos e técnicas de pesquisa bibliográfica. Sulina.

Silva, R. M. P., Galatti, L. R., \& Paes, R. R. (2010). Pedagogia do esporte e iniciação esportiva tardia: perspectivas a partir da modalidade basquetebol. Pensar a Prática, 13(1).

Tavares, F. (2013). Jogos Desportivos Coletivos: ensinar a jogar. Editora FADEUP, 165-198.

Teodorescu, L. (1977). Théorie et méthodologie des jeux sportifs.

Teodorescu, L. (1984). Problemas de teoria e metodologia nos jogos desportivos.

Werner, P., Thorpe, R., \& Bunker, D. (1996). Teaching games for understanding: Evolution of a model. Journal of Physical Education, Recreation \& Dance, 67(1), 28-33.

\section{Notas}

1 Entende-se por ação motriz o "processo de realização das condutas motrizes de um ou vários sujeitos que atuam em uma determinada situação motriz” (Parlebas, 2001, p. 41).

2 O Sistema de Classificação CAI é um critério utilizado para classificar as práticas motrizes, baseando-se nas interações motrizes estabelecidas com os demais jogadores e com o espaço de jogo (Parlebas, 2001).

3 Os Universais são divididos em sete modelos operativos que formam todo o funcionamento dos JECs, são eles: Rede de Comunicação Motriz, Rede de Interação de Marca, Sistema de Pontuação, Sistema de Troca de Papéis (Papel), Sistema de Troca de Subpapéis (Subpapel), Código Gestêmico (Gestema) e Código Praxêmico (Praxema).

4 Essas estruturas funcionais nos permite operacionalizar e concretizar a aquisição de estruturas técnico-táticas, os conhecimentos táticos, de forma teórica e prática, os quais, interligados a experiência anterior do aluno de forma crescente. Exemplo: $1 \times 1,1 \times 1+1,1 \times 2,2 \times 2+1$.

5 Desenvolvimento de sua Pedagogia do Esporte em que o jogo é fragmentado em partes (fundamentos técnicos). Cada fração é trabalhada de forma descontextualizada da exigência do jogo todo, tendo o objetivo do automatismo de um movimento. 